www.jmscr.igmpublication.org

Index Copernicus Value: 79.54

ISSN (e)-2347-176x ISSN (p) 2455-0450

crossrefDOI: https://dx.doi.org/10.18535/jmscr/v7i1.133

\title{
Early recovery of facial nerve palsy after plasmapheresis in a patient of Gullian Barre Syndrome: A Case Report
}

\author{
Authors \\ Dr Pradeepika Gangwar ${ }^{1}$, Dr Nikhil Kothari ${ }^{2}$, Dr Pradeep Bhatia ${ }^{3}$, Dr Rishabh Jaju ${ }^{4}$ \\ ${ }^{1,4}$ SR Anaesthesia and critical care AIIMS Jodhpur \\ ${ }^{2}$ Associate Professor Anaesthesia and critical care AIIMS Jodhpur \\ ${ }^{3}$ Professor and HOD anaesthesia and critical care AIIMS Jodhpur \\ Corresponding Author \\ Dr Pradeepika Gangwar
}

SR Anaesthesia and critical care AIIMS Jodhpur, India

\begin{abstract}
Bilateral facial nerve palsy is the most common manifestation of cranial nerve involvement in Gullian Barre syndrome $(G B S)$.Incidence of unilateral facial palsy although uncommon, can be seen in GBS. Standard treatment of GBS is either intravenous immunoglobulin or plasmapheresis. Here we report the role of plasmapheresis in early recovery of neuromuscular weakness and unilateral facial palsy in a patient of GBS.

Keywords: Gullian Barre Syndrome, facial nerve palsy, plasmapheresis.
\end{abstract}

\section{Introduction}

GBS is an autoimmune disease characterized by are flexic, ascending motor paralysis with or without sensory disturbances with an incidence of $1.55 / 100,000$ population. ${ }^{1}$ Seventy five percent cases of GBS are preceded by an acute respiratory or gastrointestinal tract infection. ${ }^{2}$ Proximal muscle weakness may be prominent from the onset of symptoms. Maximal weakness develops within 12-14 days of the onset of neurological symptoms. Bilateral facial palsy is present in 50\% of affected individuals but unilateral facial palsy although uncommon, can be seen in GBS patients. ${ }^{3}$ Treatment is either with intravenous immunoglobulin (IvIg) or plasmapheresis along with supportive treatment. Recovery starts from extremities followed by facial nerve recovery which may be delayed up to one month. We report a case of GBS in which there was complete recovery of facial nerve palsy and motor power within a week, after plasmapheresis.

\section{Case Description}

A 42 year old female was admitted in Intensive Care Unit (ICU) with weakness of both upper and lower limbs, inability to close right eye and deviation of angle of mouth towards left. The symptoms started with tingling sensation in all four limbs, followed by lower limbs weakness which progressed and involved upper limbs after one day. Weakness was more in lower limbs than upper limbs and proximal muscles affected more than the distal ones. She also noticed left sided facial deviation and inability to close right eye 
after two days and the patient got hospitalised on the third day after onset of symptoms (Image 1). Initially supportive treatment was given for two days then she developed mild respiratory distress with respiratory rate of 32 per minute and $\mathrm{SpO}_{2}$ 92-93\% on room air. Oxygen supplementation with nasal prongs was given but the patient never required mechanical ventilation and was hemodynamically stable. Patient had no other comorbidity. There was no prior history of trauma, dog bite, recent vaccination or any other previous significant neurological problems.

On examination her higher mental functions were normal. She was unable to close her right eye with deviation of angle of mouth to left while talking which was suggestive of lower motor neuron type of right facial nerve palsy. All other cranial nerves were normal on examination. Deep tendon reflexes were absent in all four limbs with normal superficial reflexes as corneal, conjunctival and abdominal. Muscle bulk was adequate with hypotonia of all 4 limbs, with power of $1 / 5$ in lower limbs and 2/5 in upper limbs. Sensory system, skull and spine were normal on examination. There was no bowel and bladder involvement. All routine laboratory and radiological investigations were normal. Cerebro Spinal Fluid (CSF) analysis was a cellular with elevated protein $(257 \mathrm{mg} / \mathrm{dL})$ which was suggestive of GBS. Nerve conduction study facility was not available in the institute so diagnosis of GBS was made on the basis of clinical findings and CSF report.

Four sessions of plasmapheresis were given on alternate days along with supportive treatment as facial massage, facial exercise and eye care while sleeping. There was improvement in power of all four limbs after the first session of plasmapheresis and facial recovery started after the second session of plasmapheresis. By the end of fourth session, the patient was able to walk, close both the eyes and facial deviation recovered (Image 2). Power in all limbs improved to $4 / 5$. Patient was shifted from ICU after $8^{\text {th }}$ day of admission and discharge home after two days.

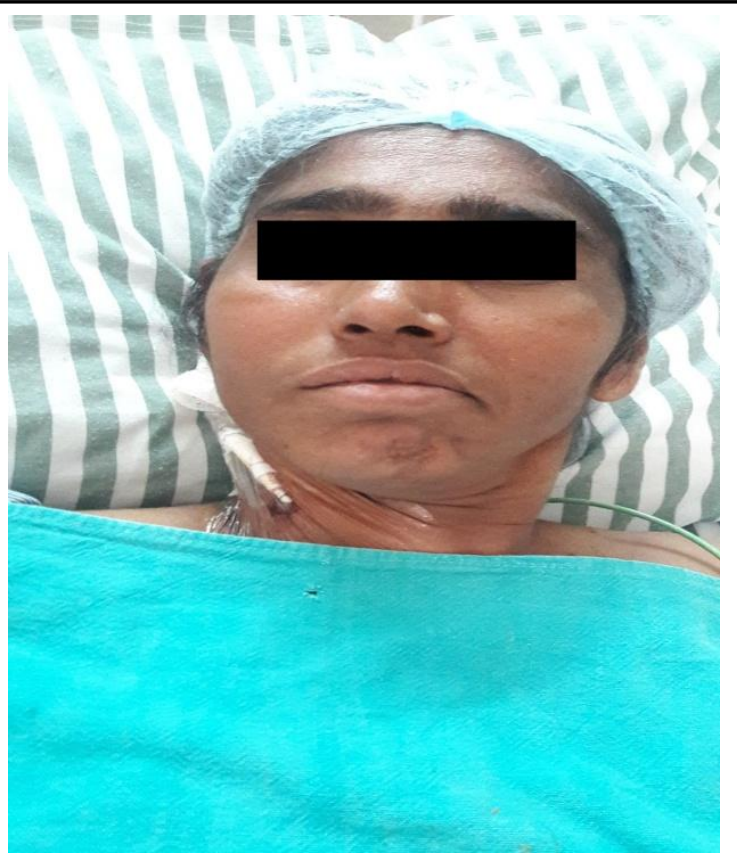

Image 1: Facial deviation towards left.

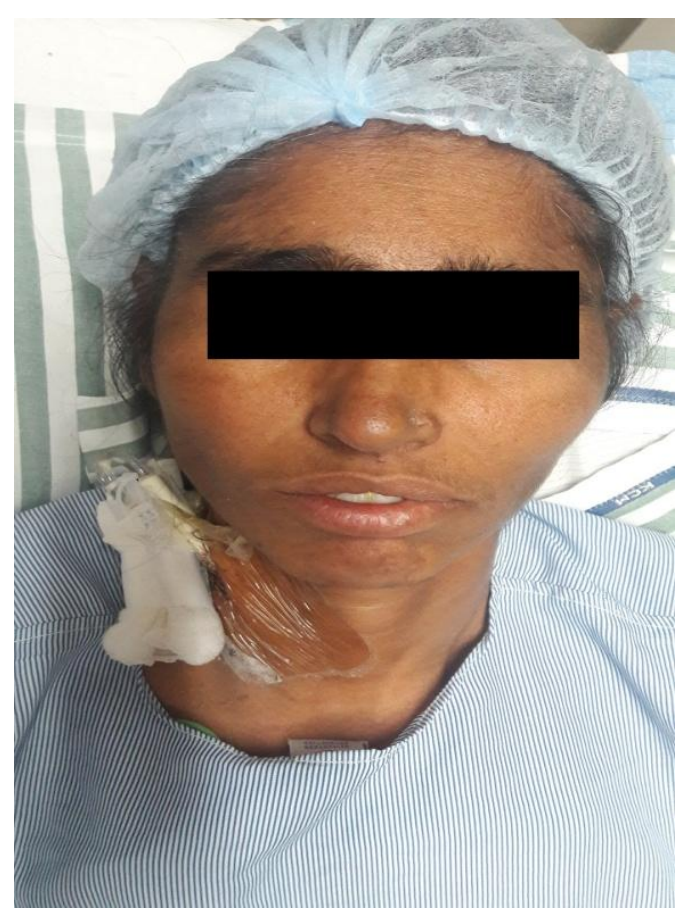

Image 2: Complete recovery of facial deviation after plasmapheresis.

\section{Discussion}

In GBS diagnosis is made by clinical symptoms, CSF examination and nerve conduction study After the diagnosis, treatment should be initiated as soon as possible For the treatment of GBS two standard modalities are avalaible i.e. either immunoglobulin ( $\mathrm{IvIg}$ ) with dose $2 \mathrm{gm} / \mathrm{kg}$ divided in five daily infusions or plasmapheresis. ${ }^{4} \mathrm{IvIg}$ is a pooled blood product and runs the risk of 
transmitting infection, and can even precipitate anaphylaxis, but is easy to administer by peripheral intravenous infusion. Plasma exchange requires central venous access and close monitoring for electrolyte abnormalities and coagulopathies. When started within 72 hours from symptom onset, IvIg has equivalent efficacy to exchange in hastening recovery in patients who require help with walking. ${ }^{5}$ Yuki et al examined the effect of the number of plasma exchanges on the reduction of immunoglobulins in 11 patients of GBS. ${ }^{6}$ A significant immunoglobulin decrease was obtained in the first two sessions but not in subsequent ones. Based on the findings they reported that at least two plasmapheresis are needed to significantly reduce the circulating immunoglobulin complexes. In previous case reports recovery of facial weakness was delayed and it was followed by recovery of extermities. Narayana et al reported a case of 35 years old female with bilateral facial palsy due to GBS. She presented with left sided lower motor neuron type facial nerve palsy later involved right side of face along with pins and needle sensations in hands and feets. ${ }^{7}$ After confirmation of AIDP with nerve conduction study and cytoalbumino dissiciation, she was initiated on a five day course of $30 \mathrm{gm}$ of IvIg from day eight. There was complete recovery of right side of face after 30 days but residual weakness on left side persisted. Another case of 65 years old man presented with weakness in both lower limbs and facial asymmetry since 5 days, was reported by Verma et al, patient was managed symptomatically as he was ambulatory. He improved over next 4 weeks, facial palsy was recovered partially after one month follow up. ${ }^{8}$ Inaloo et al reported a case of bilateral facial palsy due to GBS treated with IvIg, only right sided facial improvement was there after 3 week of follow up. ${ }^{9}$ In this case patient was treated with plasmapheresis for four sessions on alternate days started within first week of onset of symptoms. Recovery started after first plasmapheresis. There was complete facial nerve recovery after one week of treatment. She was able to walk with support at the time of discharge.

\section{Conclusion}

In this case of GBS with unilateral facial nerve palsy, when treated with plasmapheresis within first week of onset of symptoms, there was complete recovery of neuromuscular weakness and facial nerve palsy within one week of treatment. Thus, use of plasmapheresis can be tried within first week of illness, for early recovery of neuromuscular paralysis and reducing length of ICU stay.

\section{References}

1. Bogliun G, Beghi E. Italian GBS Registry Study Group. Incidence and clinical features of acute inflammatory polyradiculoneuropathy in Lombardy Italy. Acta Neurol Scand 2004;110:100-6.

2. Kamihiro N, Higashigawa M, Yamamoto T, Yoshino A, Sakata K. Acute motorsensory axonal Guillain-Barré syndrome with unilateral facial nerve paralysis after rotavirus gastroenteritis in a 2- year-old boy. Journal of Infection and Chemotherapy 2012; 18:119-23.

3. Suryanarayana B, Siddeswari R, Sudarsi B, Manohar S. A rare case report of Guillian Barre Syndrome presenting with unilateal Facial Nerve Palsy. International Journal of Scientific and Research Publications 2015;5(2):1-5.

4. Hughes RA, Raphael JC, Swan AV, Van Doorn PA. Intravenous immunoglobulin for Guillain-Barré syndrome. Cochrane Database Syst Rev 2006;1:CD002063.

5. Wijdicks E.F.M, Barohn R, Benson E. Practice parameter: Immunotherapy for Guillain-Barré syndrome. Neurology 2003;61:736-40.

6. Yuki N, Tagawa Y, Hirata K. Minimal number of plasma exchanges needed to reduce immunoglobulin in Guillain-Barré syndrome. Neurology. 1998;51:875-7. 
7. Narayanan RP, James N, Ramachandran K, Jaramillo MJ. Guillain-Barré syndrome presenting with bilateral facial nerve paralysis: a case report. Cases Journal 2008; 1: 379.

8. Verma R, Chaudhari TS, Giri P. Unilateral facial palsy in Guillain-Barre syndrome (GBS): a rare occurrence. BMJ Case Rep. 2012 Oct; pii: bcr2012007077. doi:10.1136/bcr-2012-007077.

9. Sorour Inaloo, Pegah Katibeh. GullianBarre syndrome with bilateral facial nerve palsy. Iran journal of child neurology 2014 winter;8(1):70-72. 